\title{
Erratum to: Quantitative Assessment of the Earth Observation Data and Methods Used to Generate Reference Emission Levels for REDD+
}

Brian Alan Johnson, Henry Scheyvens and Hiromitsu Samejima

\section{Erratum to:}

Chapter 14 in: M. Onoda and O.R. Young (eds.), Satellite Earth Observations and Their Impact on Society and Policy, https://doi.org/10.1007/978-981-10-3713-9_14

In the original version of the book, the belated correction from author to add the Acknowledgment has to be incorporated in Chapter 14. The erratum chapter and the book have been updated with the change.

The updated online version of this chapter can be found at https://doi.org/10.1007/978-981-10-3713-9_14 